\title{
The Introduction of Ex-ante Risk Equalisation in the Australian Private Health Insurance Market: A First Step
}

\author{
Francesco Paolucci and Amir Shmueli ${ }^{1}$
}

\section{Abstract}

In April 2007, the 'Reinsurance' arrangements in place since 1956 were replaced by a 'Risk Equalisation' scheme in the Australian private health insurance market. However, the new arrangements maintained a de facto ex-post (retrospective) claims-equalisation scheme. Equalisation transfers across competing health insurers could instead be achieved by means of a system of ex-ante prospective risk-adjusted subsidies with higher incentives for efficiency and lower incentives for selection compared to ex-post claims equalisation. This paper examines the option of introducing demographic scales for ex-ante (prospective) risk equalisation and its implications on the actual financial transfers (that is, risk-adjusted subsidies flows) across funds. The findings of this paper serve as an information basis for future policies aiming at improving efficiency and preventing selection in the Australian private health insurance market.

\section{Introduction}

The main problems with Australia's 'risk-equalisation' scheme (effectively an expost, or retrospective, claims-equalisation scheme) is the absence of incentives for efficiency, conjoined with the presence of incentives for selection in the Australian competitive market for private health insurance (PHI). A similar level of transfers across insurers could be achieved, with higher incentives for

\footnotetext{
1 The Australian National University, Francesco.Paolucci@anu.edu.au; The Hebrew University of Jerusalem. The authors wish to acknowledge the contributions of several individuals whose expertise and abilities have been crucial to the realisation of this project. We give special thanks to PHIAC for providing the data necessary to perform our analysis and, in particular, Paul Collins and Svetlana Angelkoska for their availability and technical assistance. We also appreciate the collegial support received from Andrew Gale of Medibank Private Limited, who brought to our attention and provided us with essential literature on the topic. In addition we would like to thank Jim Butler, Director of ACERH, for his support and expertise on the Australian system. Finally, we also appreciate the technical advice provided by Renata Hasanova. The views expressed in this paper are those of the authors and do not necessarily reflect those of ACERH, the Hebrew University and PHIAC.
} 
efficiency and lower incentives for selection, by replacing the current claims equalisation (CE) scheme with a system of ex-ante (prospective) risk-adjusted subsidies (that is, risk-equalisation (RE) scheme) or payments across insurers. In fact, most countries (Belgium, Israel, the Netherlands, etc.) which have introduced a centralised-finance/decentralised-delivery health system have based their 'risk-equalisation' scheme on prospective risk-adjusted subsidies supplemented, if at all, by retrospective risk-sharing arrangements (van de Ven et al. 2007; van de Ven et al. 2003; van Barneveld et al. 2001).

In this paper, the key research questions can be summarised as follows:

1. How to construct an ex-ante risk-equalisation scheme in the absence of available insurers' individual claims data?

2. What are the consequences in terms of inter-funds RE transfers (that is, riskadjusted cross-subsidies) of modifying the current ex-post retrospective agebased CE into an ex-ante prospective demographic (that is, age/gender) RE scheme within the Australia PHI market? ${ }^{2}$

Section 2 provides an overview of how the Australian private health insurance market is currently regulated and examines the case for ex-ante risk equalisation as an alternative to the current ex-post CE scheme. The data and the methods adopted in our analysis are discussed in sections 3 and 4 . Section 5 presents the results of several demographic scales for an ex-ante (prospective) riskequalisation scheme and the implications of a transition from an age-based CE to an age/gender-based RE on the inter-funds subsidies flows (that is, financial transfers). The conclusions and the policy implications are summarised in section 6 .

\section{The case for prospective risk equalisation in the Australian private health insurance market}

\section{Regulations and subsidies in the Australian PHI}

For many years following the introduction of Medicare in 1984, the proportion of PHI holders diminished from about 50 per cent to about 30 per cent in 1997, with increasing evidence of a regulation-induced selection spiral driven by community-rating with open enrolment regulations (Butler 2007; Connelly and Brown 2006; Lu and Savage 2006; Brown and Connelly 2005; Vaithianathan 2004; Butler 2003 and 2002; Hall 1999). Although the aim of community-rating

2 Demographic scales for prospective RE represent the first step towards the implementation of morbiditybased ex-ante risk equalisation (van de Ven and Ellis 2000). 
(with open enrolment) has been to implement cross-subsidies between low- and high-risk groups, it obviously creates incentives for risk-selection. In addition, community-rating (with open enrolment) does not adequately address adverseselection problems in competitive markets for voluntary health insurance (like the Australian PHI market) (van de Ven and Ellis 2000; Schut 1995).

Since 1997, the government has intervened in the Australian competitive market for PHI by introducing several forms of explicit subsidies with the aim of providing incentives to (low-risk) consumers to buy PHI and to support community-rating. Explicit subsidies include the 30-35-40 per cent premium rebate (that is, premium-related subsidy) to individuals who purchase PHI; a tax penalty of 1 per cent of taxable income payable by single individuals with taxable incomes in excess of \$70 000 p.a. (\$140 000 p.a. for couples) if they do not hold PHI (that is, the Medicare levy surcharge); and an ex-post (retrospective) CE scheme (that is, since 1956 referred to as reinsurance, renamed risk-equalisation in 2007). While collectively these measures finally stabilised PHI coverage at around $43 \%$ of the population since 2005 , they are not optimal as they lead to the trade-offs between affordability, efficiency and selection (van de Ven and Schut 2007; Paolucci et al. 2006; van de Ven and Ellis 2000; van de Ven et al. 2000). As pointed out by van de Ven and Schut (2007), the only escape from these trade-offs is ex-ante (prospective) risk-equalisation. To the extent that some high-risk individuals are insufficiently subsidised, the ex-ante risk-equalisation payments can be complemented by one or more of the above-mentioned forms of subsidy: premium-based subsidies, ex-post claims-equalisation and implicit cross-subsidies enforced by premium-rate restrictions for a specified insurance coverage. The better the subsidies are adjusted for relevant risk factors, the less these complementary strategies are needed, and the less severe is the trade-off (van de Ven and Schut 2007; Paolucci et al. 2006).

\section{The risk-equalisation scheme since $2007^{3}$}

In April 2007, the reinsurance scheme introduced in 1956 was replaced by a risk-equalisation scheme. The reinsurance scheme in place until 2007 functioned as an ex-post claims-sharing arrangement (that is, claims equalisation) among insurers. In particular, equalisation of funds was based on 79 per cent of insurers' hospital claims costs for individuals aged over 65 and for all members (including those younger than 65) with more than 35 days in hospital during the year. The Private Health Insurance Administration Council (that is, the regulator/ sponsor) received quarterly information from the health funds, calculated an average claims cost for each $\mathrm{State}^{4}$ and calculated an average claims cost for

3 For a detailed overview of the previous reinsurance and current risk-equalisation schemes in Australia, we refer to Connelly et al. 2010, Armstrong et al. 2010, and Armstrong and Paolucci 2010).

4 Note that the Australian Capital Territory is included in New South Wales. 
each fund operating in each of those States. Where funds had higher than the average claims, they received money from the reinsurance pool, and where they had lower than the State average, they paid money into the pool. The pool is a quarterly zero-sum calculation.

Although the so-called risk-equalisation scheme has replaced and modified the reinsurance scheme in many ways (see below), de facto it maintained the features of an ex-post (retrospective) claims-equalisation (CE) rather than an exante (prospective) risk-equalisation (RE) scheme. The current $\mathrm{CE}$ is 'a system to share the hospital costs and some general treatment costs of high risk groups among private health insurers', with the purpose of allowing 'a more equitable treatment of health funds with different coverage of high-risk groups to support community rating' (PHIAC 2007). First the Age-Based Pool (ABP) has been introduced with the purpose of matching more closely the increase in claims by age and, in particular, it replaces the two age-bands (+/- 65 years old) of the reinsurance scheme with a set of eight age groups with varying proportions of the claims cost increasing with the age of the claimant (see Table 1).

Table 1: From the 'old two age-bands system' to the 'new ABP'

\begin{tabular}{|l|l|l|}
\hline Age & $\begin{array}{l}\text { \% of claims-costs pooled } \\
\text { under 'Reinsurance' }\end{array}$ & $\begin{array}{l}\text { \% of claims-costs pooled } \\
\text { under 'Risk-equalisation' }\end{array}$ \\
\hline $0-54$ & $0 \%$ & $0 \%$ \\
\hline $55-59$ & $0 \%$ & $15 \%$ \\
\hline $60-64$ & $0 \%$ & $43 \%$ \\
\hline $65-69$ & $79 \%$ & $60 \%$ \\
\hline $70-74$ & $79 \%$ & $70 \%$ \\
\hline $75-79$ & $79 \%$ & $76 \%$ \\
\hline $80-84$ & $79 \%$ & $78 \%$ \\
\hline $85-89$ & $79 \%$ & $82 \%$ \\
\hline $90-94$ & $79 \%$ & $82 \%$ \\
\hline $95+$ & $79 \%$ & $82 \%$ \\
\hline
\end{tabular}

The pooling of claims costs for all individuals with hospitalisation in excess of 35 days in a 12-month period was replaced by a High Cost Claims Pool (HCCP), where benefits in excess of $\$ 50000$ in a 12-month period are pooled (after the operation of the age-based pooling). In practice, the HCCP shares the costs of high-cost claimants where they are not otherwise shared by the ABP. The HCCP was implemented to protect small funds from large claims in lieu of genuine excess-loss compensation schemes (van de Ven and Schut 2007; Paolucci et al. 2006). Risk equalisation transfers about $\$ 50$ million per quarter among the health funds. PHIAC expects this to grow as the insured population continues to age (PHIAC 2007). 
The old reinsurance scheme only included hospital costs, whereas from 2007 these costs are eligible for pooling within the ex-post (retrospective) CE scheme: hospital benefits, hospital substitute benefits, chronic-disease management program benefits, and high-cost claimants' benefits (Division 69, Private Health Insurance Act 2007).

\section{The construction and operation of ex-ante risk equalisation}

The construction of ex-ante prospective RE scheme by the regulator consists of three parts:

(a) the choice of risk adjusters; namely, the characteristics of the enrolees and of the insurers which best predict future healthcare expenditures. This choice is shaped by statistical considerations, data availability, social norms regarding responsibility (for example, smoking) and discrimination/affirmative action (such as minorities' health), and the need to minimise the information asymmetry between the insurers and the regulator.

(b) the creation of optimal cost groups; namely, where the variance in cost between groups is maximised and variance within groups is minimised.

(c) setting the prospective capitation rates (relative-risk scale) for the (exhausting and mutually exclusive) groups defined by the set of the risk adjusters chosen.

Ideally, the set of risk adjusters includes socio-demographic and health status characteristics of the enrolees, which are risk factors likely to be used by insurers for risk selection or to risk-rate premiums in the PHI market, ${ }^{5}$ modified, maybe, by public health considerations. In reality, this set is unknown to the regulator, and the risk-based grouping of the population for the calculation of the risk-adjusted subsidies depends on the availability of data, the statistical skills and the sophistication of the regulator. In most countries, the set of risk adjusters adopted by the regulators includes demographic characteristics (such as age and gender), and in some countries health status indicators (for example, Diagnostic Cost Groups and Pharmaceuticals Cost Groups in the Netherlands). The prospective rates are ideally calculated from actual costs of a representative sample of the enrolees as reported by the insurers using individual claims data. At least during the first years after the introduction of a risk-equalisation scheme, the insurers' individual claims data are not readily available in most countries - either because of technical and IT difficulties or because of the

5 Although premium rate restrictions (i.e. community-rating per product per insurer) have been applying already for a long time as a regulatory tool to prevent insurers from risk-rating in the Australian private health insurance market, there is anecdotal evidence of premium differentiation via product differentiation (Paolucci 2008). 
insurers' reluctance to provide commercial data. In such cases, other sources reporting on healthcare utilisation by the population together with individual characteristics can be used.

The introduction of ex-ante (prospective) risk equalisation and the improvement of the current formula by adding to age other sensitive risk factors such as gender (that is, a demographic model), even without using insurers' individual claims data, would be largely beneficial in terms of reducing insurers' incentives for risk selection and would, overall, increase efficiency and affordability compared to the current ex-post (retrospective) risk equalisation. Ex-ante risk equalisation is based on the notion of a 'standardised person'. Demographic scales (that is, age/sex) can be derived, first, by calculating the age-/ex-specific means ('the cell method') of the measure of cost (utilisation), and then by dividing them by the overall mean. The 'standardised person' (SP) is the average which is indicated by 1 (SPs). The scale values indicate to how many SPs every person is equivalent, according to her age and sex. This approach is convenient for policy purposes, since it separates between the size of the budget and the budget ('voucher') per SP, on the one hand, and the risk-adjusted allocation of the budget among the insurers, on the other. In some cases, 'total medical care costs' are unavailable, while the available data include utilisation of specific services (for example, visits to the dentist, to GPs, inpatient hospital nights, and so on).

An overall scale is calculated in the following way. Suppose there are two health services covered by PHI - hospitalisations and GP visits. Denote the unit cost of an inpatient day by $\mathrm{p}_{\mathrm{s}}$ and the unit cost of a visit to a GP by $\mathrm{p}_{\mathrm{b}}$. If the yearly mean number of hospitalisation days in the risk-equalisation group $i$ is $s_{i}$ and the mean number of visits to GPs is $b_{i}$, the mean total cost in group $i$ is given by $c_{i}=p_{s} s_{i}+p_{b} b_{i}$. Similarly, the grand mean cost in the population is $c=p_{s} s+p_{b} b$, where $s$ and $b$ are the mean yearly hospitalisation days and visits to GPs in the population. The total relative scale is:

$$
\begin{aligned}
& \mathrm{c}_{\mathrm{i}} / \mathrm{c}=\left(\mathrm{p}_{\mathrm{s}} \mathrm{s}_{\mathrm{i}}+\mathrm{p}_{\mathrm{b}} \mathrm{b}_{\mathrm{i}}\right) /\left(\mathrm{p}_{\mathrm{s}} \mathrm{s}+\mathrm{p}_{\mathrm{b}} \mathrm{b}\right)=\mathrm{v}_{\mathrm{s}}\left(\mathrm{s}_{\mathrm{i}} / \mathrm{s}\right)+\mathrm{v}_{\mathrm{b}}\left(\mathrm{b}_{\mathrm{i}} / \mathrm{b}\right) \\
& \text { where } \mathrm{v}_{\mathrm{s}}=\mathrm{p}_{\mathrm{s}} \mathrm{s} /\left(\mathrm{p}_{\mathrm{s}} \mathrm{s}+\mathrm{p}_{\mathrm{b}} \mathrm{b}\right) \text { and } \mathrm{v}_{\mathrm{b}}=\mathrm{p}_{\mathrm{b}} \mathrm{b} /\left(\mathrm{p}_{\mathrm{s}} \mathrm{s}+\mathrm{p}_{\mathrm{b}} \mathrm{b}\right) .
\end{aligned}
$$

In other words, the scale is a weighted average of the service-specific scales in physical quantities, with the weights being the relative share of the cost of the service in total cost. The total budget for allocation among insurers is predetermined according to society's priorities and definition of acceptable costs (that is, costs to be reimbursed, Schokkaert et al. 2006), and is allocated among insurers according to the insurers' shares in total standardised persons. According to the Australian ex-post claims-equalisation scheme, a certain percentage of the claims (the percentage is increasing with age) is virtually collected into the Risk Equalisation Trust Fund (REF), and then allocated to the 
insurers according to their market shares. The fundamental difference between ex-ante risk equalisation and ex-post claims equalisation (that is, the current Australian RE scheme) is that in ex-ante risk equalisation the total budget is set a priori according to society's priorities, and is allocated to the insurers according (and only) to the age (and potentially other predetermined riskfactors) structure of their populations. Ex-post claims equalisation re-distributes a 'budget' set exogenously, mainly made of the age-based contributions of all insurers, which are derived from the actual claims (costs) according to market share. The age structure of the populations determines the contribution rather than the transfer. The percentage contributions define quite arbitrarily the socially 'acceptable costs' out of total costs (benefit paid) which flow in the pool to be re-distributed across funds.

\section{Data}

Since insurers' individual-claims data are not publicly available and individual records on the use of public healthcare are segmented between Medicare, the States and the Commonwealth, preventing linkage on the individual level in the near future, risk equalisation in Australia can at present be based only on scales derived from available breakdowns of the utilisation of health services and benefits by State, age and sex. While it is agreed that demographic scales are not sufficient to remove the incentives for selection (van de Ven and Ellis 2000), international experience shows that for reasons related to data availability and social and political acceptance, the implementation of a new ex-ante riskequalisation scheme should begin with (socio-) demographic scales (van de Ven et al. 2003). After the accumulation of some experience and the development of IT and individual level databases, one can search for sophisticated health-based scales (Stam et al. 2010).

In the following sections, we derive the demographic scales of an ex-ante RE system based on three public data sources (PHIAC 2007; AIHW 2006-07; and the NHS 2004-05) with the purpose of selecting the 'preferred' scales to adopt in further elaborations of the current risk-equalisation scheme in Australia. While the AIHW and the NHS data refer to the entire Australian population, PHIAC data refer to the insured population (about 45 per cent of the Australian population voluntarily chooses to purchase PHI). ${ }^{6}$ Although the most relevant population for the purposes of risk equalisation among insurers is represented by $\mathrm{PHI}$ holders, it is also subject to changes in insurance ownership patterns over

6 PHIAC 2007, 2008. 
time, and therefore the derived scales would need to be verified and updated often. Since at present CE is done by State, we present the scales by State as well. The NHS data, however, are too small to derive State-specific scales.

To simulate the implications of replacing the current ex-post (retrospective) age-based CE scheme with an ex-ante (prospective) RE scheme on the financial transfers across funds (that is, inter-funds risk-adjusted subsidies payments based on age and gender), we use PHIAC aggregate data (2007) on health insurers' actual benefits (that is, claims costs). ${ }^{7}$

\section{Risk equalisation scales in Australia using publicly available data}

\section{Scales derived from PHIAC data}

The data available from PHIAC include the number of hospital days, episodes (separations), fees and benefits, and the number of services used, fees and benefits for the general treatment policies. For the overall scale we used the sum of benefits for hospitals and treatments policies. ${ }^{8}$ We used the number of hospital policy owners (9.4 million) as the relevant population size.

Figure 1 presents the four hospitalisation scales for men and women.

Up to age 75, all the scales are approximately similar. Above age 75, the scales based on days in hospital increase rapidly, while the scale based on episodes stabilises on 4 among men and 2.5 among women. The fees and benefits scales are in between. We note that if inpatient care is paid for by prospective percase methods (DRG), the benefits should follow closely the episodes scale. If reimbursement is based on per-diem, the benefits should follow the day-scale. A possible explanation for the gap is that 'days' include long-term hospitalisation which is not covered, or is covered only partially, by the private insurers.

\footnotetext{
7 Most insurers (30 out of 39) formally authorised PHIAC to allow us to access aggregate (age-gender groups) health expenditures data per insurer for hospital care and general treatment services. The remaining nine insurers were treated as one insurer to cover the entire market.

8 Doing so, we introduced a slight inaccuracy to the calculation, since the owners of hospitals policies and of general treatments policies do not match exactly. Data on ownership of each type of policy by age and sex and state are not available, but using total population data from 2007 indicates that the inaccuracy is small: out of 10.8 million insured, 9.0 million have both policies, 0.4 million own hospital policy only, and 1.4 million persons own general treatments only.
} 


\section{Figure 1A: PHIAC hospitalisation scales: Men}

\section{(1=mean)}

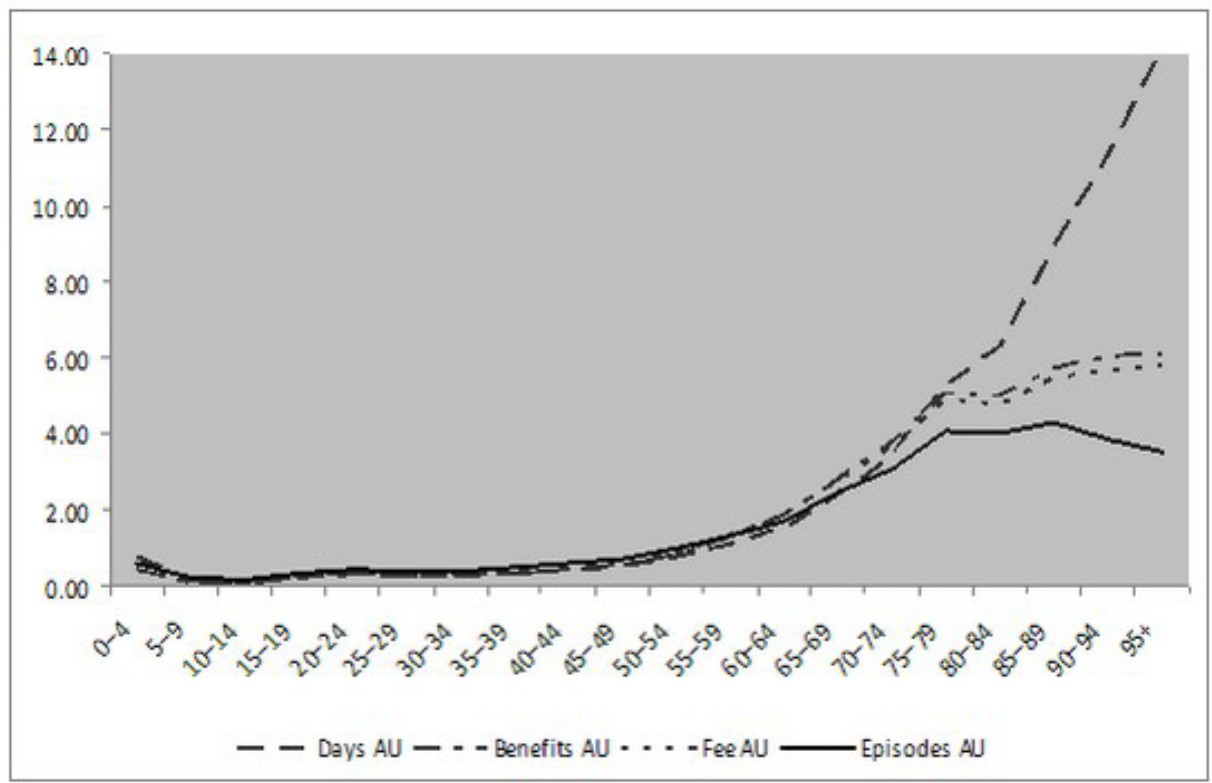

Figure 1B: PHIAC hospitalisation scales: Women (1=mean)

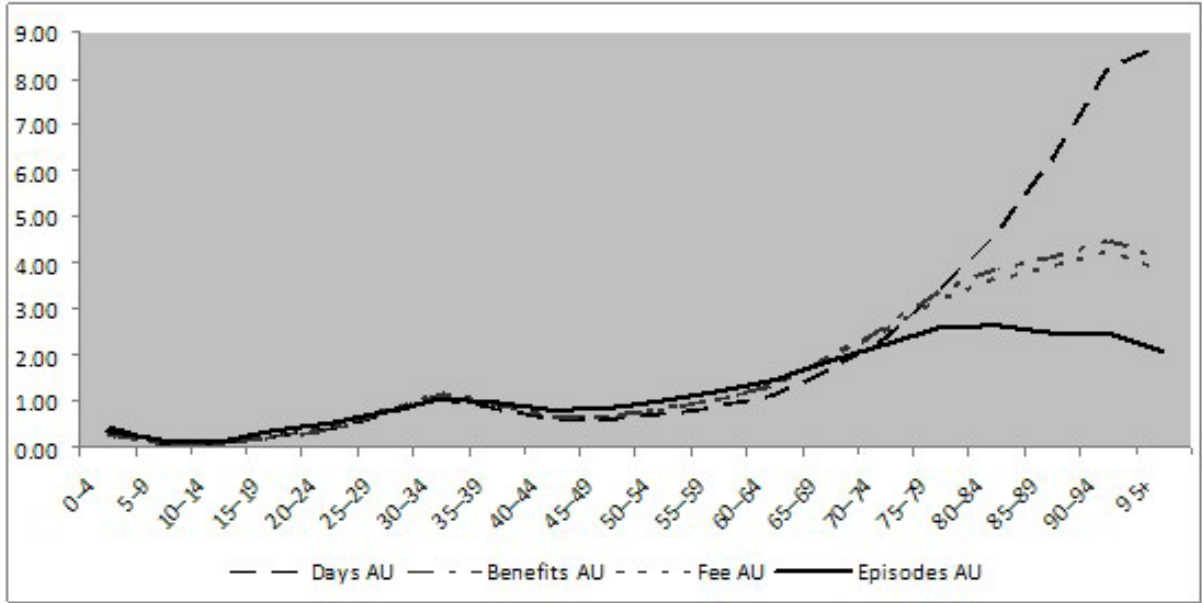


Figure 2A: PHIAC general treatments scales: Men (1=mean)

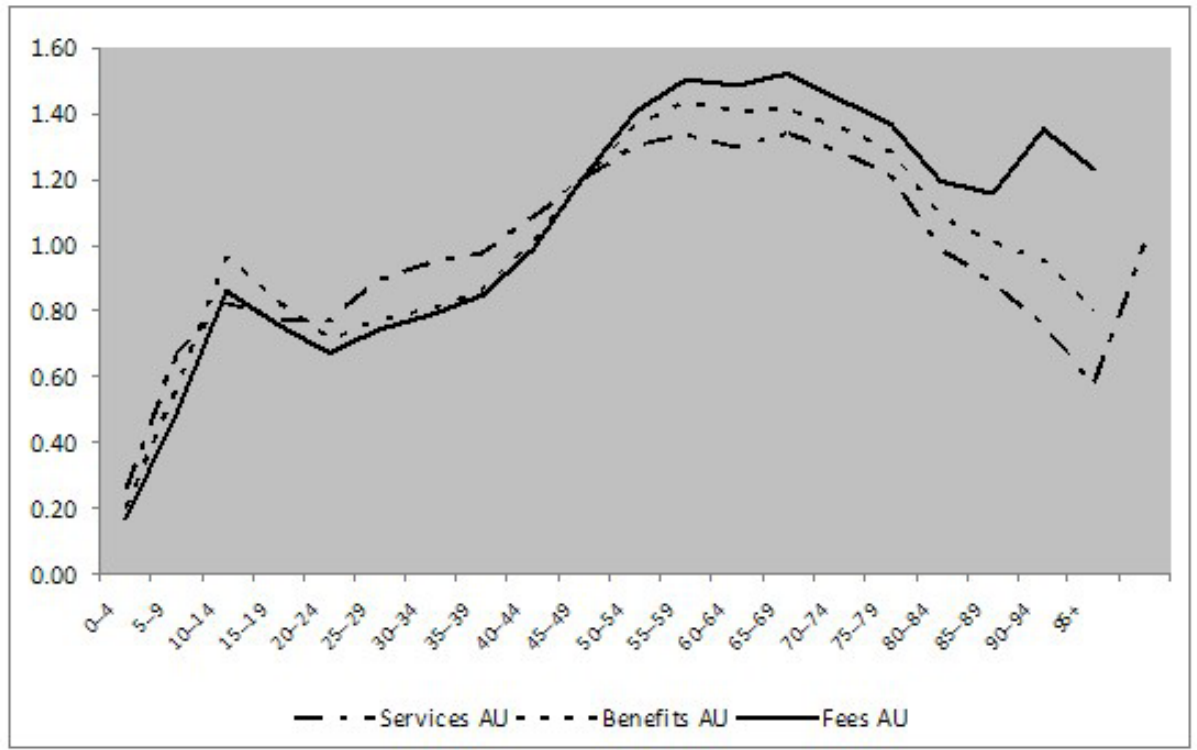

Figure 2B: PHIAC general treatments scales - Women (1=mean)

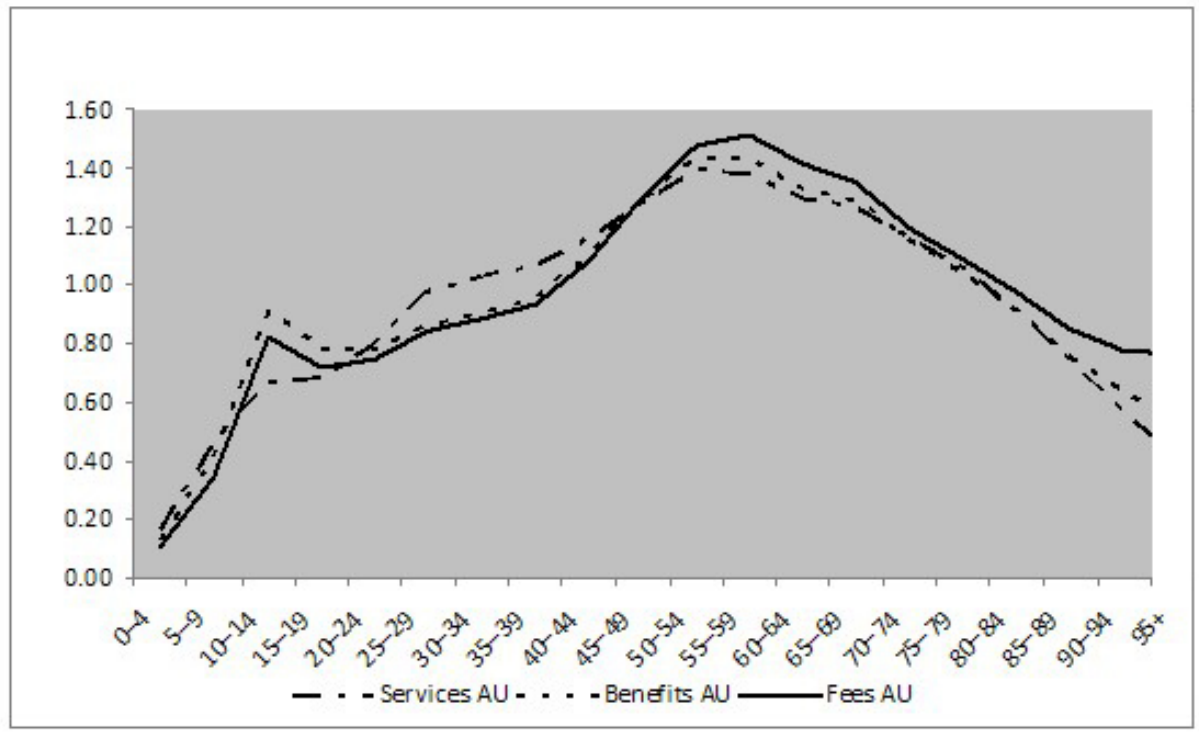


Figure 2 presents the three general treatments scales: number of services (episodes), benefits and fees.

The scales are quite similar below age 80, particularly for women. The higher scale for fees indicates the relatively higher co-payments paid by elderly persons. We chose to focus subsequently on the benefits scale.

\section{Scales derived from NHS 2004-05 data}

Although suffering from recall problems and other biases, population surveys on use of services have been used extensively for risk adjustment (Stam et al. 2010). The relatively small number of persons prevented the calculation of state-specific scales, and the age groups were enlarged to 10-year intervals. We built service-specific scales for dental care visits, visits to GPs and specialists out of hospitals, in hospital outpatient visits (ER, same-day admissions), and inpatient overnights. In order to combine these into an overall scale, we used cost weights that were obtained from AIHW (2006) and were modified to the services discussed, as indicated in Table 2:

Table 2: Adapted costs weights (AlHW 2004-05)

\begin{tabular}{|l|c|}
\hline Dental care & $9.9 \%$ \\
\hline $\begin{array}{l}\text { Out-of-hospital services (GPs, specialists, other } \\
\text { medical) }\end{array}$ & $22.6 \%$ \\
\hline $\begin{array}{l}\text { In-hospital outpatient visits (ER, same-day } \\
\text { admissions) }\end{array}$ & $35.2 \%$ \\
\hline Inpatient overnights & $32.3 \%$ \\
\hline Total & $100.0 \%$ \\
\hline
\end{tabular}

Figure 3 presents the scales for men and women separately using weighted data. 
Figure 3A: National Health Survey (2004/05)

Service-specific and overall scales: Men

(1=mean)

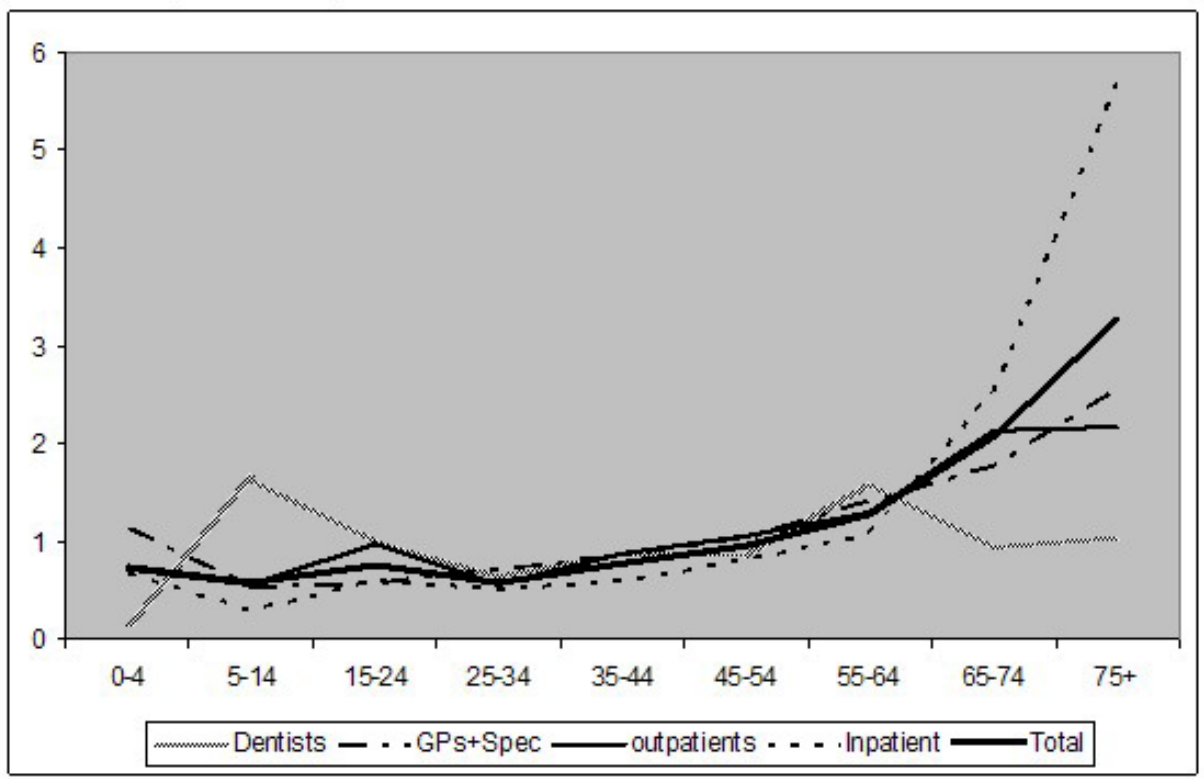

Figure 3B: National Health Survey (2004/05)

Service-specific and overall scales: Women

(1=mean)

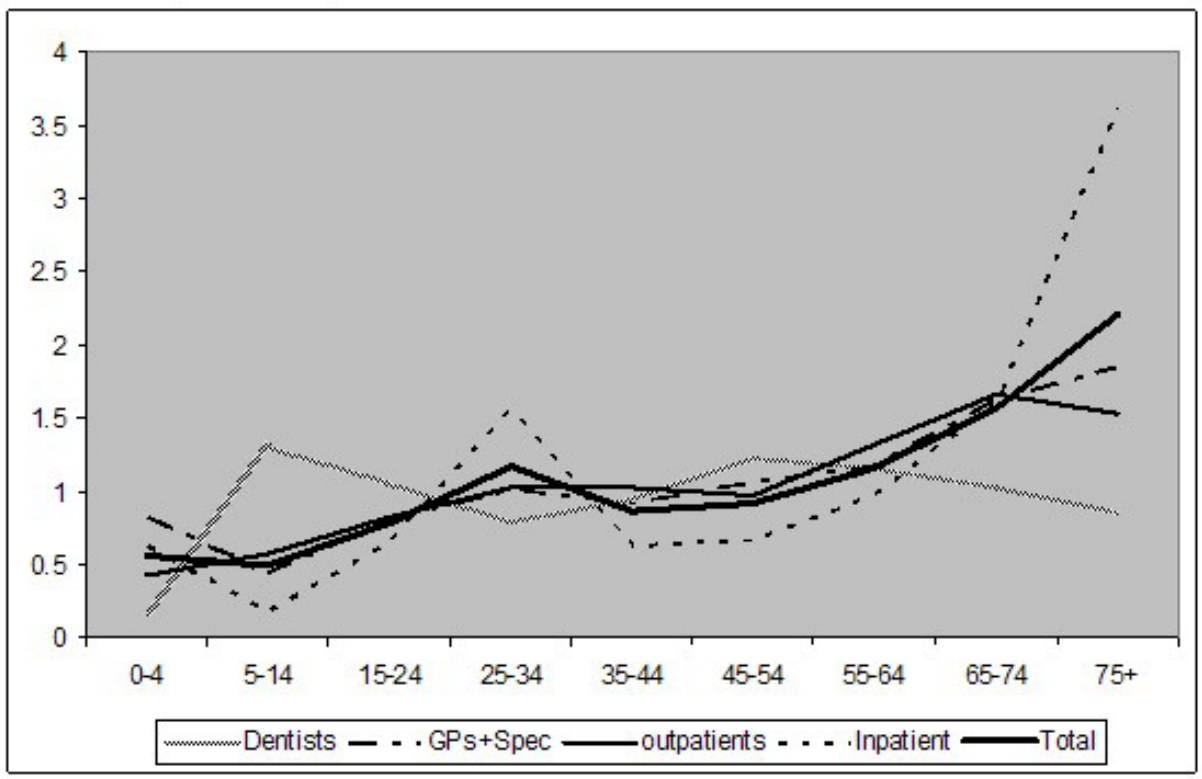




\section{Scales from other sources}

Other scales can be derived from AIHW 2006-07 data (that is, hospitalisation scales) and from Medicare-MBS 2005-06 data. The AIHW data include separations (episodes) and days in public and private hospitals by age, sex and state, including one-day admissions. The scales for TAS, ACT and NT include public hospitals only (the AU scales include all hospitalisations, however). The NT scales are unreliable due to small cells and were disregarded. The MBS data include benefits such as medical and surgical care and services, X-rays, laboratory tests, electro-cardiograms, and so on. Unfortunately, the PBS data are not available by age and sex.

\section{Comparisons: Hospitalisation-days scales and overall scales}

Figure 4 brings together the inpatient-days scales calculated from PHIAC, AIHW and NHS. The AIHW and NHS scales were 'stretched' to fit the PHIAC's detailed age groups. Up to age 75 , the scales are remarkably close. For some reason, women aged 25-40 in the NHS report more inpatient days. Above age 75, among men, the PHIAC and AIHW scales are quite close, considering the truncation of the AIHW scale. Among women aged 80+, the AIHW scale is much higher than that based on PHIAC data. As discussed previously, the gap might be explained by long-term care days for uninsured women.

Four overall scales emerge: the PHIAC scales, which are based on benefits; the NHS scales, which are based on aggregating service-specific use scales; the MBS-Inpatient Days scales and the MBS-Inpatient Separations scales. The latter two are based on aggregation of the MBS scales with the AIHW inpatient scales of days and separations respectively. The weights used in this aggregation are 65 per cent for inpatient care, and 35 per cent for the MBS care (AIHW, Health expenditure by area of expenditure, 2005-06). Figure 5 presents these scales, together with a fifth overall scale, which is taken from Table 8.10 of Australia Health 2008. 
Figure 4A: Combined inpatient-days scales:Men (1=mean)

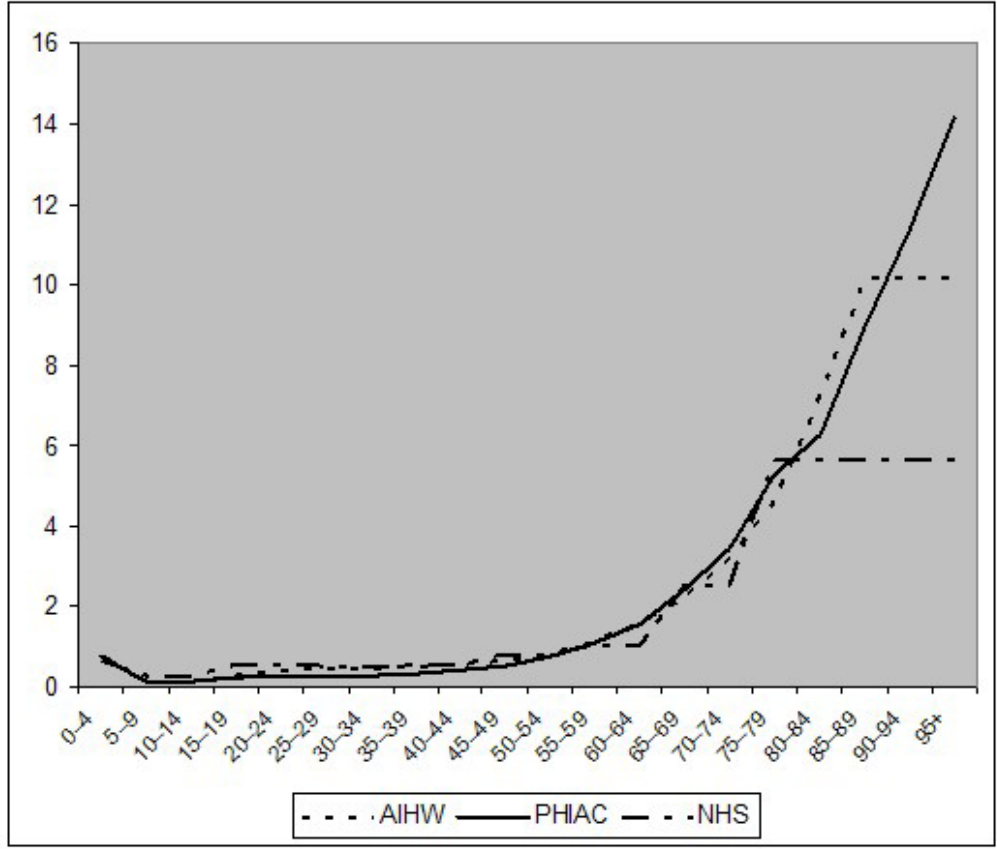

Figure 4B: Combined inpatient-days scales: Women (1=mean)

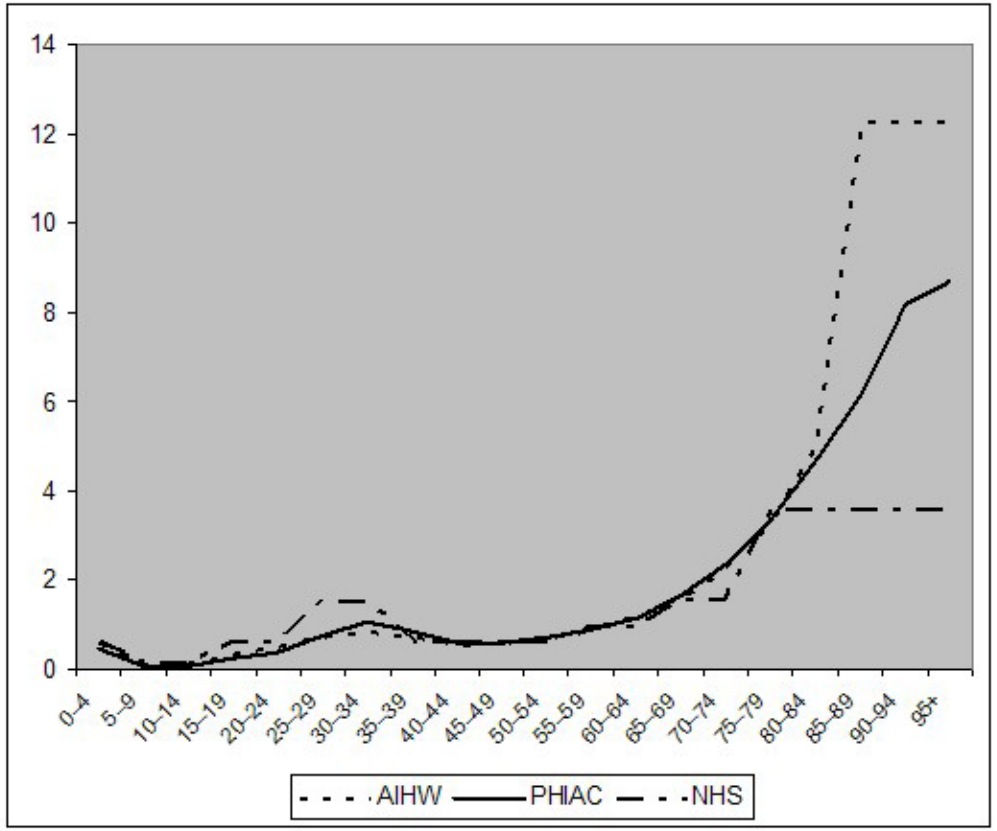




\section{Figure 5A: Overall scales: Men}

(1=mean)

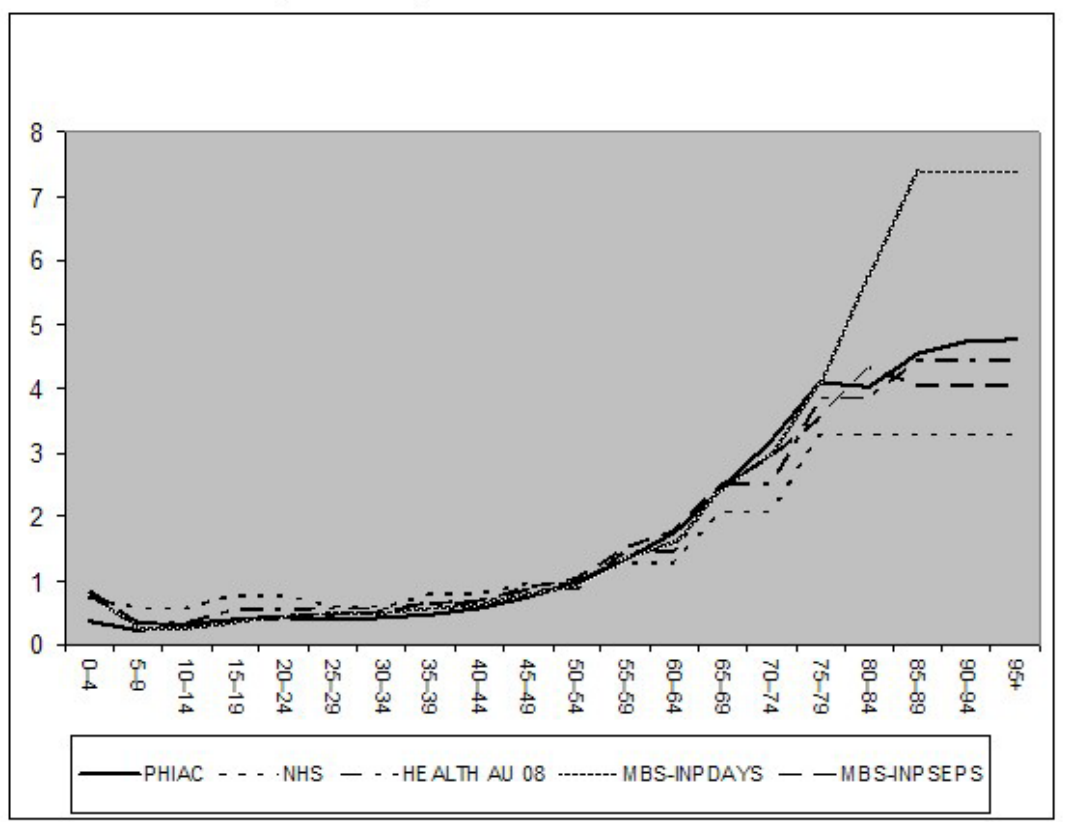

Figure 5B: Overall scales: Women

(1=mean)

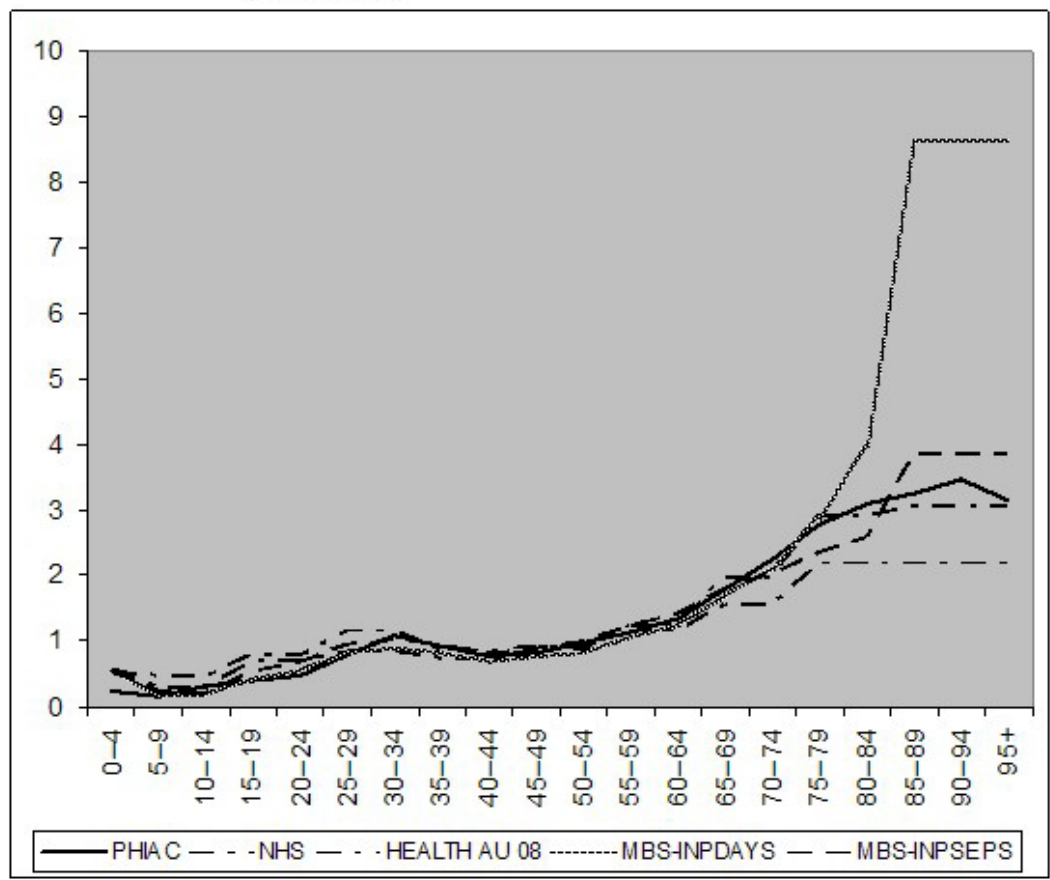


This scale is based on 'allocated expenditures by diseases' that covers about 65 per cent of total health expenditures (excluding hospital non-admitted patient care, community health, public health, administration, other health practitioners, transport, aids and appliances).

Up to age 60, all scales for both men and women are quite close. Above age 60, the NHS scale is considerably below the others. Up to age 75, the four remaining scales are quite similar; but above age 75, the MBS-INPDAYS scale takes off rapidly, while the PHIAC, MBS-INPSEPS and HEALTH AU 08 scales remain close to each other.

The critical question, therefore, is whether inpatient days or inpatient benefits or separations represent more accurately the resources devoted to inpatient care. If it is inpatient days, the MBS-INPDAYS scales should be adopted. Alternatively, either of the two remaining scales (PHIAC or MBS-INPSEPS) is appropriate and can be used as demographic scales for prospective RE in Australia.

\section{The effects of the introduction of ex-ante risk equalisation on inter-funds transfers}

Based on the above overall age-gender scales and the current ABP (age-based pool; that is, RE using age as the only risk factor) allocation of benefits (that is, claims costs), we simulate the effect of moving towards ex-ante RE on the benefits share for selected insurers in each State and in Australia as a whole. Specifically, we use the overall scales based on PHIAC data (2007) to calculate the number of standardised persons for each insurer in each State. The post-RE benefits share is the share of standardised persons per insurer on the total of standardised persons in each State and in Australia; and the pre-RE benefits share is the original distribution of benefits across the insurers. The post-RE ABP-based benefit share is the pre-RE benefits share modified by the ABP transfers. The gain or loss for each insurer is the difference between the ex-ante RE size of benefits and the benefits resulting from the ABP distribution. We note that the total budget (the sum of the original benefits across insurers) always remains constant.

From Table 3 it is clear that a transition from the current ex-post CE to an ex-ante RE scheme will result in gainers and losers among insurers. The identity of these gainers and losers differs across States. ${ }^{9}$ In total Australia, about two-thirds of the funds would lose from the transition from $\mathrm{CE}$ to RE and the financial losses at the fund level would range from $-\$ 1.781\left(\mathrm{I}_{15}\right)$ - that is, 0.01 per cent of the total budget $(=\$ 21.156 .000)$ - to $-\$ 548.222\left(\mathrm{I}_{18}\right)$ - that is, 2.6 per cent of the total budget (where $\mathrm{I}_{\mathrm{i}}$ indexes the identity of insurers operating in the Australian PHI market). The remaining one-third of the funds would gain from the transition and the financial gains would range from $\$ 2.823\left(\mathrm{I}_{29}\right)-0.013$ per cent of the total budget - to $\$ 345.725\left(\mathrm{I}_{30}\right)-1.63$ per cent of the total budget. The main gainers (among the insurers included in this simulation) will be insurers $\mathrm{I}_{30}(=\$ 345.725), \mathrm{I}_{17}(=\$ 321.303)$ and $\mathrm{I}_{14}(\$ 92.565)$. The main losers will be $\mathrm{I}_{18}(-\$ 548.222), \mathrm{I}_{13}(-\$ 137.748)$ and $\mathrm{I}_{4}(-\$ 93.285)$.

9 For reasons of space we haven't included the transfers at the State level, which might be made available upon request to the authors. 
The Introduction of Ex-ante Risk Equalisation in the Australian Private Health Insurance Market

Table 3: Effect of switching from ex-post CE to ex-ante RE on inter-funds transfers at the national level in Australia (population and benefits are for 30.6.08, PHIAC data)

\begin{tabular}{|c|c|c|c|c|}
\hline FID $^{1}$ & $\begin{array}{l}\text { Pre-RE benefit } \\
\text { shares }(\%)^{2}\end{array}$ & $\begin{array}{l}\text { Post-RE ABP benefit } \\
\text { shares }(\%)^{3}\end{array}$ & $\begin{array}{l}\text { Post-RE Ex-ante } \\
\text { benefit shares }(\%)^{4}\end{array}$ & $\begin{array}{l}\text { Gain/ Loss } \\
(000 \text { AU\$) })^{* 5}\end{array}$ \\
\hline 11 & 0.141 & 0.154 & 0.107 & -10.057 \\
\hline 12 & 0.159 & 0.195 & 0.082 & -24.089 \\
\hline 13 & 1.361 & 1.011 & 1.280 & 56.965 \\
\hline 14 & 3.414 & 3.876 & 3.435 & -93.285 \\
\hline 15 & 0.057 & 0.069 & 0.042 & -5.741 \\
\hline 16 & 0.476 & 0.537 & 0.379 & -33.524 \\
\hline 17 & 0.168 & 0.192 & 0.116 & -16.177 \\
\hline 18 & 1.353 & 1.259 & 1.610 & 74.194 \\
\hline 19 & 0.373 & 0.267 & 0.250 & -3.612 \\
\hline 110 & 0.073 & 0.062 & 0.079 & 3.639 \\
\hline $\mid 11$ & 0.441 & 0.448 & 0.435 & -2.704 \\
\hline 112 & 0.415 & 0.363 & 0.352 & -2.450 \\
\hline 113 & 16.839 & 17.987 & 17.336 & -137.748 \\
\hline I14 & 27.954 & 28.615 & 29.053 & 92.565 \\
\hline I15 & 1.687 & 1.466 & 1.458 & -1.781 \\
\hline 116 & 0.313 & 0.294 & 0.253 & -8.789 \\
\hline 117 & 5.481 & 4.476 & 5.995 & 321.303 \\
\hline 118 & 10.533 & 10.859 & 8.267 & -548.222 \\
\hline 119 & 1.940 & 1.699 & 1.830 & 27.697 \\
\hline 120 & 0.170 & 0.188 & 0.141 & -10.128 \\
\hline 121 & 0.559 & 0.537 & 0.422 & -24.334 \\
\hline 122 & 0.423 & 0.521 & 0.261 & -54.996 \\
\hline 123 & 0.082 & 0.104 & 0.058 & -9.645 \\
\hline 124 & 0.347 & 0.285 & 0.245 & -8.486 \\
\hline 125 & 1.976 & 1.784 & 1.994 & 44.439 \\
\hline 126 & 0.428 & 0.453 & 0.397 & -11.744 \\
\hline 127 & 0.085 & 0.087 & 0.062 & -5.206 \\
\hline 128 & 0.630 & 0.598 & 0.803 & 43.369 \\
\hline 129 & 0.038 & 0.028 & 0.041 & 2.823 \\
\hline 130 & 22.085 & 21.583 & 23.217 & 345.725 \\
\hline TOTAL & 100.000 & 100.000 & 100.000 & 0.000 \\
\hline
\end{tabular}

${ }^{1}$ Funds identity.

${ }^{2}$ Share of claims per fund prior to the operation of the current ex-post claims-equalisation scheme.

${ }^{3}$ Share of claims per fund after the operation of the current ex-post risk-equalisation scheme.

${ }^{4}$ Share of claims per fund after the operation of the new ex-ante risk-equalisation scheme.

${ }^{5}$ Financial gains/losses per fund per quarter resulting from the transition from ex-post to ex-ante.

${ }^{*}$ PHIAC scale-based benefit share - ABP benefit share. 
The 'new' redistribution based on ex-ante demographic RE matches the agegender structure better than under the current ex-post $\mathrm{CE}$, reducing the incentives for selection. Considering that according to RE the total benefits are taken as an ex-ante budget, incentives for efficiency will also be increased.

\section{Conclusions}

In this paper, we examine several options for an ex-ante (prospective) riskequalisation scheme and its implications on the inter-funds subsidies flows. Since individual claims data are not publicly available, we analyse aggregate age/sex-based scales derived from PHIAC data; and scales derived from the National Health Morbidity Data (AIHW); from Medicare (MBS); and from the National Health Survey (NHS). From these sources we calculate several risk-adjustment demographic scales, to derive the 'preferred' scales to use in further elaborations of the risk-equalisation scheme in Australia. The choice of preferred scale depends on whether inpatient days or inpatient benefits or separations represent more accurately the resources devoted to inpatient care. If it is inpatient days, the preferred scale is MBS-INPDAYS, otherwise either of the two remaining scales (PHIAC or MBS-INPSEPS) is equally appropriate and can be used for a prospective risk-equalisation scheme in Australia.

Although risk equalisation in Australia can be improved at present only using demographic scales derived from publicly available data on the utilisation of health services, it is clear that demographic scales are not sufficient to remove the incentives for risk selection by the insurers (van de Ven and Ellis 2000). The next crucial step is to derive the scales for other potential relevant risk factors, such as health-based scales. These scales could be derived by linking state hospital data and expenditure data with federal medical and pharmaceutical expenditure data at the individual level. For instance, Donato and Richardson (2006) report on an exploratory inquiry into the Australian application of the US version of the diagnostic cost groups (DxCGs) risk-adjustment method to a large Australian hospital inpatient data set (1996-97 and 1997-98) for New South Wales. ${ }^{10}$ Their study focuses on the potential usefulness of individual-level risk-adjustment methods for validating measurement of performance across healthcare providers and for allocating resources efficiently and equitably across population groups of different area health services (AHS) in New South Wales. In line with studies performed in other countries, they find that diagnosis-based

10 Although Donato and Richardson (2006) has been the first study on risk adjustment in Australia based on a large hospital data set, previous studies on the topic have been conducted by Duckett and Agius (2002) and Anthioc and Walsh (2004). 
risk adjustment offers the potential to refine measures of case-mix adjustment of population groups, providing a more reliable assessment of the efficiency of different AHS (in NSW) compared to age/sex demographic methods.

The combination of inpatient hospital diagnostic information with pharmaceutical and self-assessed health status information has been shown to perform significantly better than demographic and/or inpatient-only models alone (for example, in the Netherlands - see Stam et al. 2010).

In particular, the introduction of ex-ante (prospective) risk equalisation and the improvement of the current formula (that is, based on more sensitive risk factors than those currently adopted, such as gender), even without using insurers' individual claims data, would be largely beneficial in terms of reducing insurers' incentives for risk selection and would increase overall efficiency compared to the current ex-post (retrospective) CE.

\section{References}

Antioch, K. M. and Walsh, M. K. 2004, 'The risk-adjusted vision beyond casemix (DRG) funding in Australia. International lessons in high complexity and capitation', European Journal of Health Economics 5(2): 95-109.

Armstrong, J., Paolucci, F. and van de Ven. W. P. P. M. 2010, 'Risk equalisation in voluntary health insurance markets', Health Policy 98(1): 1-2.

Armstrong, J., Paolucci, F., McLeod, H. and van de Ven, W. P. P. M. 2010, 'Risk Equalisation in Voluntary Health Insurance Markets in Three Countries', Health Policy 98(1): 39-49.

Armstrong, J. and Paolucci, F. 2010, 'Risk equalisation in Ireland and Australia: A simulation analysis to compare outcomes', Geneva Papers on Risk and Insurance - Issues and Practice 35(4): 521-38.

Australian Bureau of Statistics 2006, National Health Survey 2004-2005.

Australian Institute of Health and Welfare (AIHW) 2008, Health Expenditure Australia 2006-07, Cat. No. HWE 42, AIHW, Canberra, December.

2006, Australian hospital statistics 2004-05, Cat. no. HSE 41, AIHW, Canberra, December.

Biggs, A. and Buckmaster, L. 2007, 'Private Health Insurance Bill 2006', Bills Digest, No.81, 8 February, Parliament of Australia, Department of Parliamentary Services, Canberra. 
Brown, H. S. III and Connelly, L. B. 2005, 'Lifetime cover in private insurance markets', International Journal of Health Care Finance and Economics 5(1): 75-88.

Butler, J. R. G. 2007, 'Adverse selection in Australian private health insurance: recent trends', presentation to the ACERH Research Forum on Health Care Financing and Private Health Insurance: International Experience and Recent Australian Trends, 24 September, Canberra. Available at: http://www.acerh. edu.au/research_forums.php.

2002, 'Policy change and private health insurance: Did the cheapest policy do the trick?' Australian Health Review 25(6): 33-41.

2003, 'Adverse selection, genetic testing and life insurance - lessons from health insurance in Australia', Agenda 10(1): 73-89.

Connelly, L. B., Paolucci, F., Butler, J. R. G. and Collins, P. 2010, 'Risk equalisation and voluntary health insurance markets: The case of Australia', Health Policy 98 (1): 3-14.

Connelly, L. B. and Brown, H. S. III 2006, 'Lifetime subsidies in Australian private health insurance markets with community rating', Geneva Papers on Risk and Insurance — Issues and Practice 31(4): 705-19.

Donato, R. and Richardson, J. 2006, 'Diagnosis-based risk adjustment and Australian Health System Policy', Australian Health Review 30(1): 83-99

Duckett, S. J. and Agius, P. A. 2002, 'Performance of diagnosis-based riskadjustment measures in a population of sick Australians', Australian and New Zealand Journal of Public Health 26(6): 500-507.

Hall, J., De Abreu, Lourenco R. and Viney, R. 1999, 'Carrots and sticks - the fall and fall of private health insurance in Australia' Health Economics 8(8): 653-60.

Lu, M. and Savage, E. 2006, 'Do financial incentives for supplementary private health insurance reduce pressure on the public system? Evidence from Australia', CHERE Working Paper 2006/11, Centre for Health Economics Research and Evaluation (CHERE), University of Technology Sydney, August.

Medicare Australia. Unpublished data: 2005-06 Medicare Provider Data and Medicare Benefit Schedule (MBS) data: Servicing Provider Data.

Paolucci, F. 2011, 'Health financing and insurance: options for design' in Frech, H., Zweifel, E. and Springer, P. (series eds), Developments in Health Economics and Public Policy. 
2008, 'Risk equalisation in voluntary health insurance markets: the case of Australia', a presentation to ACERH Research Forum on Risk Equalisation in Health Insurance Markets, The Australian National University, 10 June, Canberra. Available at: http://www.acerh.edu.au/research_forums.php.

Paolucci, F., Schut, F. T., Beck, K., Van de Voorden, C., Gress, S. and Zmora, I. 2007, 'Supplementary health insurance as a tool for risk selection in mandatory basic health insurance markets', Health Economics, Policy and Law 2(2): 173-92.

Paolucci, F., den Exter, A. and van de Ven, W. P. M. M. 2006, 'Solidarity in competitive health insurance markets: analysing the relevant EC legal framework', Health Economics, Policy and Law 1(2): 107-26.

Parliament of Australia 2007, Private Health Insurance Act 2007, No. 31 of 2007 as amended, Canberra, April.

Private Health Insurance Administration Council (PHIAC) 2008a, Hospital Treatment Coverage, PHIAC, Canberra (downloaded from http://www.phiac. gov.au, figures taken from membershipall.xls).

2008b, PHIAC A: All States, PHIAC, Canberra (downloaded from http:// www.phiac.gov.au).

2007, Operations of the Private Health Insurers: Annual Report 2006-07, PHIAC, Canberra.

Schokkaert, E., Beck, K., Shmueli, A., van de Ven, W., Van de Voorde, C. and Wasem, J. 2006, 'Acceptable costs and risk adjustment: Policy choices and ethical trade-offs', CES - Discussion paper series (DPS) 06.19: 1-38.

Schut, F. T. 1995, 'Competition in the Dutch health care sector', dissertation, Erasmus University, Rotterdam.

Stam, P. J., van Vliet, R. C. and van de Ven, W. P. 2010, 'Diagnostic, pharmacybased, and self-reported health measures in risk equalization models', Medical Care 48(5): 448-57.

Vaithianathan, R. 2004, 'A critique of the private health insurance regulations', Australian Economic Review 37(3): 257-70.

Van Barneveld, E. M., Lamers, L. M., van Vliet, R. C. J. A. and van de Ven, W. P. M. M. 2001, 'Risk sharing as a supplement to imperfect capitation: a tradeoff between selection and efficiency', Journal of Health Economics 20: 147-68. 
van de Ven, W. P. M. M., Beck, K., van de Voorde, C., Wasem, J. and Zmora, I. 2007, 'Risk adjustment and risk selection in Europe: 6 years later', Health Policy 83: 162-79.

van de Ven, W. P. M. M. and Schut, F. T. 2007, 'Risk equalization in an individual health insurance market: the only escape from the trade-off between affordability, efficiency and selection', paper prepared for FRESH-thinking (http://fresh-thinking.org/publications/pubs.htm).

van de Ven, W. P. M. M., Beck, K., Buchner, F., Chernichovsky, D., Gardiol, L. and Holly, A. et al. 2003, 'Risk adjustments and risk selection on the sickness fund insurance market in five European countries', Health Policy 65: 75-98.

van de Ven, W. P. M. M. and Ellis, R. P. 2000, 'Risk adjustment in competitive health insurance markets', in Culyer, A. J. and Newhouse, J. P. (eds), Handbook of Health Economics, Amsterdam: Elsevier: 755-845.

van de Ven, W. P. M. M., van Vliet, R. C. J. A., Schut, F. T. and van Barneveld, E. M. 2000, 'Access to coverage for high-risk consumers in a competitive individual health insurance market: via premium rate restrictions or riskadjusted premium subsidies?' Journal of Health Economics 19(3): 311-39. 